\title{
Single-dose meloxicam treatment improves standing ability of low-vitality dairy calves
}

\author{
L. Kovács, ${ }^{1 *} \odot$ F. L. Kézér, ${ }^{2}$ F. Ruff, ${ }^{3}$ M. Samardzija, ${ }^{4} \oplus$ and O. Szenci ${ }^{5} \oplus$ \\ ${ }^{1}$ Institute of Animal Sciences, Hungarian University of Agriculture and Life Sciences, Guba Sándor u. 40, Kaposvár, H-7400 Hungary \\ ${ }^{2}$ Bona Adventure Ltd., Peres utca 44, Gödöllö, H-2100 Hungary \\ ${ }^{3}$ Department of Methodology, Hungarian Central Statistical Office, Keleti Károly utca 5-7, Budapest, H-1024 Hungary \\ ${ }^{4}$ Clinic for Obstetrics and Reproduction, University of Zagreb, Heinzelova 55, 10000 Zagreb, Croatia \\ ${ }^{5}$ Department of Obstetrics and Food Animal Medicine Clinic, University of Veterinary Medicine Budapest, Üllö-Dóra major, H-2225 Hungary
}

\begin{abstract}
A promising strategy to improve newborn calf survival could be the administration of nonsteroidal antiinflammatory drugs (NSAID) especially in cases of low vitality calves born from difficult calvings. The objective of this clinical trial was to determine the effect of a single-dose meloxicam treatment [target dosage $=$ $0.5 \mathrm{mg} / \mathrm{kg}$ ad usum veterinarium (A.U.V.) injection] on parameters of lying behavior of Holstein-Friesian dairy calves $(\mathrm{n}=180)$ born to eutocic $(\mathrm{n}=98)$ compared with dystocic dams $(n=82)$. Animal-based measures included newborn calf vitality (low, 1-6 scores; normal, 7-12 scores, scored immediately after birth), calf sex and birth weight, parity of the dam, and early maternal behavior (the time spent licking the calf). Parameters of the complex lying behavior were recorded during the first $48 \mathrm{~h}$ after delivery and included (1) the time spent standing, (2) lying down frequency, (3) the longest standing bout, (4) the average duration of standing bouts, (5) the first successful standing, and (6) the first attempt to stand. None of the parameters related to lying behavior were influenced by the parity of the dam, calf sex, or birth weight and maternal grooming behavior. The latency and the first attempt to stand were not influenced by the NSAID treatment; however, the time spent standing, the longest standing bout, and the average duration of standing indicated increased standing ability of meloxicam-treated calves with low vitality, but not in normal-vitality calves. The latency to stand and first attempt to stand were both increased by dystocia. Based on the present findings, sensory measurement of parameters of lying behavior during the immediate neonatal period might be useful to evaluate the efficiency of NSAID protocols. A single-
\end{abstract}

Received May 6, 2021.

Accepted October 12, 2021.

*Corresponding author: Kovacs.Levente@uni-mate.hu dose meloxicam treatment showed considerable promise for improving standing ability of low-vitality calves.

Key words: nonsteroidal antiinflammatory drug, lying behavior, standing ability, dairy calf, meloxicam

\section{INTRODUCTION}

In dairy cattle, about half of all perinatal losses occur during the first $48 \mathrm{~h}$ of life (Vermorel et al., 1983; Schuijt, 1990); therefore, clinical concerns of this period are extensively studied. The so-called "weak calf syndrome" presents as a newborn calf that is weak, unable, or slow to rise, stand, or feed (Ward, 1973; Mee, 2013). Dystocia is a growing problem in dairy farms (Mee, 2008), and low-vitality calves are often born to dystocic dams (Lombard et al., 2007; Kovács et al., 2016). Reduced vitality can result from injury, inflammation, inability to maintain homeostasis, hypoxia, acidosis (Breazile et al., 1988; Besser et al., 1990; Szenci, 2003), or pain (Mellor and Stafford, 2004). These physiological effects can have behavioral repercussions, such as having reduced motivation to perform natural behaviors for survival, including standing up and suckling colostrum after birth (Barrier et al., 2013). Very little is known about the pain experienced by newborn calves following birth and hence little consideration has been given to managing it. Therefore, the early assistance to newborn calves is crucial, especially in cases of calves with low neonatal vitality and standing ability.

A promising strategy to improve newborn calf vitality and survival could be the administration of nonsteroidal antiinflammatory drugs (NSAID; Murray and Leslie, 2013). Although between 28 and 39\% of dairy (Huxley and Whay, 2006; Moggy et al., 2017) and 13\% of beef producers (Murray et al., 2016b) reported using NSAID in calves after a difficult birth at least occasionally, only a low number of studies have investigated the benefits of NSAID use in dairy calves following dystocia (Murray et al., 2016a; Gladden et al., 2019). The NSAID class of drugs acts by inhibiting cyclo- 
oxygenase isoenzymes (COX-1 and COX-2) to prevent the inflammatory cascade and reduces prostaglandin synthesis (Anderson and Muir, 2005). Meloxicam is a COX-2 preferential inhibitor NSAID (Brideau et al., 2001; Beretta et al., 2005), having a mean plasma halflife of approximately $26 \mathrm{~h}$ in cattle (EAEMP, 2007). It causes fewer negative side effects and has high bioavailability with a prolonged half-life in comparison with other NSAID (Coetzee, 2013). Meloxicam treatment had a positive effect in cases of calf diarrhea (Todd et al., 2010), dehorning (Heinrich et al., 2009, 2010), castration, and respiratory disease (Coetzee et al., 2009) and tended to increase starter intake of preweaning dairy calves when it was provided in pill form before consumption of colostrum replacer (Clark et al., 2020).

As parameters of the complex lying and standing behavior reflect calf adaptation to stressful situations (Kovács et al., 2018), we hypothesized that they may also provide indirect evidence of the adaptation success to the extrauterine life and be useful in the evaluation of the efficiency of NSAID treatments in dairy calves. It is not known how difficulties at calving and calf vitality influence standing ability of newborns and whether the onset and the duration of standing can be supported by NSAID treatment. The objective of the study was to test whether a single-dose NSAID treatment increases standing ability of newborn dairy calves within the first $24 \mathrm{~h}$ after delivery.

\section{MATERIALS AND METHODS}

\section{Animals and Experimental Farm}

All methods and the applied procedures on the animals were performed in accordance with the relevant guidelines and regulations of the Pest County Government Office, Department of Animal Health (Permit Number: PE/EA/1973-6/2016) that approved the study. The experiment was carried out on a large-scale dairy farm in Hungary $\left(47^{\circ} 18^{\prime} 191^{\prime \prime} \mathrm{N}, 18^{\circ} 48^{\prime} 336^{\prime \prime} \mathrm{E}\right)$, which has a herd of more than 1,000 lactating Holstein cows. The farm was visited for an 8-mo period in 2020 [temperature; average $/$ minimum $/$ maximum $\left({ }^{\circ} \mathrm{C}\right)$ : $12.3 / 6.4 / 24.8]$.

Two hundred Holstein-Friesian calves born between February and May $[\mathrm{n}=100$; temperature: average/ minimum/maximum $\left.\left({ }^{\circ} \mathrm{C}\right)=12.8 / 6.7 / 25.7\right]$ and between September and December $[\mathrm{n}=100$, temperature: average $/$ minimum $/$ maximum $\left.\left({ }^{\circ} \mathrm{C}\right)=12.0 / 6.2 / 24.2\right]$ were enrolled into the study.

Newborn calves were removed from the dams $2 \mathrm{~h}$ after birth. Within $2.5 \mathrm{~h}$ after calving the dam was milked, and colostrum was provided to the newborn calves by nipple bottle. Calves were routinely fed 4 times a day with $1.65 \mathrm{~L}$ of fresh-cow colostrum per feeding during the first $48 \mathrm{~h}$ of life. Newborns were housed individually in $1.65 \times 1.20 \mathrm{~m}$ plastic calf hutches (CalfOtel Comfort, VDK Products B.V.) with a $1.60-\mathrm{m}^{2}$ exercise pen. Both the hutch and pen areas were bedded with straw. Management of calving and feeding of newborns during the first $48 \mathrm{~h}$ of life was constant during the experimental period.

\section{Experimental Design and NSAID Treatment}

Calvings took place in the prepartum group pen or, if continuous supervision or obstetrical assistance was required at calving, in a separated maternity pen. Assistance by well-trained farm personnel was performed at the latest within 90 min after the appearance of the amniotic sac in the vulva as described previously by Kovács et al. (2016). Calving ease was scored by the first author based on the recordings of a closed-circuit camera system including $2 \mathrm{~d} /$ night outdoor network bullet cameras (Vivotek IP8331, Vivotek Inc.) installed above the pre-calving group pen allowing the identification of individual cows, whereas in cases of individual calvings, 2 portable video cameras (Legria HF M36, Canon) were used after placing cows into the maternity pen. During scoring, the ease of calving, the number of personnel aiding at birth, and the delay of the second stage of labor were considered following Mee (2004):

- Score 1 = eutocia, no assistant needed during delivery $(\mathrm{n}=98)$,

- Score 2 = delay (from 60 to 90 min after appearance of the amniotic sac) in the second stage of labor (between the appearance of the amniotic sac and delivery of the calf) or calving assisted by one person without the use of mechanical traction (light dystocia, $\mathrm{n}=47$ ),

- Score $3=$ mechanical traction of a calf with a calf puller or assistance by 2 or more people with considerable force (severe dystocia, $\mathrm{n}=52$ ), and

- Score $4=$ severe dystocia surgery needed $(n=3)$.

Twin calves $(\mathrm{n}=14)$ and dystocic calves with posterior presentation $(\mathrm{n}=6)$ were excluded from the 200 animals because they are prone to extremely low vitality due to prolonged labor and amniotic aspiration, respectively. These criteria were established a priori. Finally, a total of 180 newborns were used in the study, calves with score 1 were considered as eutocic (EUT, n $=98)$ and calves with scores 2 to 4 were considered as dystocic (DYS, $\mathrm{n}=82$ ).

Immediately after delivery, calves were blocked by birth date (even date/odd date) and randomly assigned to receive a single-dose subcutaneous injection from a 
numbered individual treatment vial containing 1 of 2 treatments: either meloxicam (Melovem, AgriHealth), with a target dosage of $0.5 \mathrm{mg} / \mathrm{kg}$ ad usum veterinarium injection (A.U.V.) injection ( $\mathrm{n}=90 ; \mathrm{n}=48 \mathrm{EUT}, \mathrm{n}=$ 42 DYS $)$ or a placebo solution $(\mathrm{n}=90 ; \mathrm{n}=50 \mathrm{EUT}$, $\mathrm{n}=40$ DYS). Each milliliter of Melovem injection contained $20.0 \mathrm{mg}$ of meloxicam and $150 \mathrm{mg}$ of ethanol (as preservative). The objective of the study was to increase standing ability. The placebo used in this study was a visually identical product to Melovem and had an identical base formulation of the product without the active ingredient, meloxicam. Farm personnel treated the animals and were blinded to the medication group. After treatments were done, no further animals were excluded from the experiment.

Neonatal vitality was assessed immediately after birth by a trained individual who was blind to treatment groups. The criteria recommended by Szenci (1982) were used in a 12-score linear scoring system; by considering sucking drive as an additional parameter as follows: (1) muscle tone (2: normal, 1: low, 0: toneless); (2) erection of the head (2: erected head, 1 : head requiring support; 0: head dropping); (3) muscle reflexes (2: normal reflectory movements, 1: reduced number and intensity of reflectory movements, 0 : limbs extended); (4) mucus membrane color (2: pink, 1: pale pink, 0: cyanotic); (5) heart rate (2: normal/regular 120-220 beats per min, 1: bradycardia/irregular $<120$ beats per min, 0 : absent); and (6) sucking drive (2: intensive, 1: reduced, 0: absent). Following the vitality assessment, scores were summed up. Newborns with scores 1 to 6 were considered as low-vitality calves, whereas newborns with scores 7 to 12 were considered as normal-vitality calves.

\section{Maternal Behavior}

Postpartum grooming behavior of the dams was video recorded with the closed-circuit camera system (Vivotek IP8331, Vivotek Inc.) in cases when calving occurred in the prepartum group pen or with portable cameras (Legria HF M36, Canon Inc.), allowing the best view on the animals in cases of individual calvings in the maternity pen. The time spent licking the calf's head or body (tongue in contact with the calf's head or body) were analyzed by the second author, who was blind to the treatment following Jensen (2012). Continuous video footage was used for the analysis recorded for the first $2 \mathrm{~h}$ after birth.

\section{Parameters of the Complex Lying Behavior}

A HOBO Pendant G data logger (Onset Computer Corp.) was used to record the $g$ force and tilt on the $x$-, $y$-, and $z$-axes on a scale of -1 to 1 . The logger was wrapped in gauze to provide cushioning and attached to the lateral side of the right rear leg by the second author immediately after delivery using Copoly flexible cohesion bandage $(\mathrm{M}+\mathrm{H}$ Vet Ltd.) above the metacarpophalangeal joint of the calves as advised by Swartz et al. (2016).

Recordings lasted for $48 \mathrm{~h}$ following birth. Data were downloaded and exported to Excel (Microsoft Corp.) and analyzed using the Onset HOBOware Software (Onset Computer Corp.). Information from the $x$-axis was used to evaluate lying down and standing with a 30-s sampling interval, considering that lying down and standing bouts can be short during the early neonatal period. Cut-off values of $g<0.75$ for lying down $g \geq$ 0.75 for standing were determined based on results of previous validation process (Bonk et al., 2013) and were used to categorize logger readings as a specific behavior. Using Excel, $g$ forces of the $x$-axis were converted to either a lying or standing minute, and the change from a standing minute to a lying minute was used to denote a lying bout. Output was also edited to examine the effect of using a 1-min event filter to remove potentially erroneous readings of lying or standing events (Ledgerwood et al., 2010; Bonk et al., 2013). This filter converted behaviors of a 1-min duration back to the original behavior that preceded it.

Long-term parameters of the complex lying behavior were calculated for the first $48 \mathrm{~h}$ of the neonatal life and included the time spent standing, lying down frequency, the longest standing bout, and the average duration of standing bouts (long-term parameters). The latency to stand (first successful standing) and the first attempt to stand were used as short-term measures. According to Campler et al. (2015) the first successful standing was considered when the calf was standing upright with all 4 legs fully extended for longer than $5 \mathrm{~s}$, whereas the first attempt to stand was considered when the calf was partially standing upright with both hind legs extended and with front legs still under body but without reaching a fully upright position.

\section{Statistical Analysis}

Statistical analyses were performed in the $\mathrm{R}-3.3 .1$ statistical environment and language ( $\mathrm{R}$ Core Team 2017). Significance was set at the level of $P<0.05$ in all cases. General linear mixed models (GLMM) were fit to the data (Pinheiro and Bates, 2000; package nlme in R) with random effects for each calf. The birth weight of the calf (ranging between 32.4 and $53.6 \mathrm{~kg}$ ) and the time spent licking the calf (ranging between 8.2 and $113.5 \mathrm{~min}$ ) were added to the models as covariates. To consider the most important circumstances around 
Table 1. Characteristics of calvings and number of calves involved in the study according to birth weight, sex, and vitality (means \pm SEM)

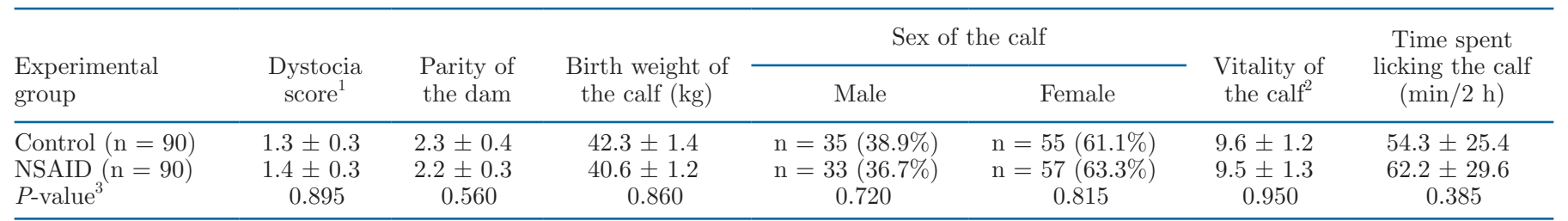

${ }^{1}$ The degree of dystocia was scored using a 1 to 4 scale following Mee (2004).

${ }^{2}$ Neonatal vitality was scored using a 12 -score linear scoring system.

${ }^{3}$ Significance is based on Welch's 2-sample $t$-test in cases of dystocia score, parity of the dam, birth weight, vitality of the calf, and time spent licking the calf. The proportions of male and female calves were compared between control and nonsteroidal antiinflammatory drug (NSAID) groups with Pearson's chi-squared test.

calving, several fixed effects were entered in the models. Fixed effects were parity of the dam (primiparous vs. multiparous), sex (male vs. female), vitality of the calf (low vs. normal), and ease of calving (EUT vs. DYS) as well as NSAID treatment (treated vs. nontreated) and their interaction. The covariate birth weight of the calf was consistently entered into the model first. After birth weight, time spent licking the calf was entered into the model, and then fixed effects were added. The time spent standing, lying down frequency, longest standing bout, average duration of standing bouts, latency to stand, and first attempt to stand were inserted into the models as response variables. Data were tested for constant variance (Levene's test) and the Shapiro-Wilk test was used for testing the equality of error variances. Log-transformation of behavioral parameters was applied to satisfy the normality and variance homogeneity assumptions of the models, and Cohen's $d$ was calculated to estimate effect size on behavioral parameters. For multiple comparisons, the Tukey-Kramer correction was used. Comparisons of independent variables between NSAID and control calves were made by the Wilcoxon rank-sum test.

\section{RESULTS AND DISCUSSION}

From the 180 experimental calvings, 42, 59, and 79 calves were born to first-, second-, and third-parity cows, respectively. A total of 68 calves had low vitality, whereas 132 calves had normal vitality at birth. Comparison of independent variables between control and NSAID calves is shown in Table 1. Parameters of the complex lying behavior of NSAID-treated and control calves and significant interactions with vitality are presented in Table 2.

Although the ability of a calf to stand was found to be influenced previously by the birth weight and the sex of the calf (Barrier et al., 2012), none of the parameters of the complex lying behavior measured here during the first $48 \mathrm{~h}$ after delivery were influenced by sex or birth weight. The parity of the dam had also no influence on the elements of the complex lying behavior of the newborns. Among the investigated behavioral parameters, lying down frequency was not affected by vitality, treatment, or calving ease (eutocia or dystocia).

As it was hypothesized, a single-dose NSAID treatment improved most of the parameters related to standing ability of newborns; however, low-vitality calves benefited more from the administration of a single-dose meloxicam than calves with normal vitality. Although the latency and the first attempt to stand were not influenced by treatment, significant effects of treatment, vitality, and their interaction were found on the time spent standing, longest standing bout, and average duration of standing bouts (Table 2). These results indicate that NSAID treatment had a favorable

Table 2. Parameters of the complex lying behavior of nonsteroidal antiinflammatory drug (NSAID)-treated and control calves (means \pm SD) ${ }^{1}$

\begin{tabular}{|c|c|c|c|c|c|c|}
\hline \multirow[b]{2}{*}{ Parameter } & \multirow[b]{2}{*}{ NSAID } & \multirow[b]{2}{*}{ Control } & \multirow[b]{2}{*}{ Interaction } & \multicolumn{2}{|c|}{ Low vitality } & \multirow{2}{*}{$\begin{array}{l}\text { Cohen's } d \\
(95 \% \text { CI })^{2}\end{array}$} \\
\hline & & & & NSAID & Control & \\
\hline Time spent standing $(\mathrm{h})$ & $6.8 \pm 1.8$ & $6.3 \pm 1.5$ & Vitality & $5.2 \pm 1.3$ & $7.9 \pm 1.6$ & 0.84 \\
\hline Longest standing bout ( $\min )$ & $30.4 \pm 10.6$ & $26.4 \pm 9.4$ & Vitality & $28.7 \pm 6.2$ & $21.0 \pm 5.3$ & 0.81 \\
\hline Average duration of standing bouts (min) & $8.2 \pm 6.0$ & $6.6 \pm 4.8$ & Vitality & $7.5 \pm 4.1$ & $3.9 \pm 2.6$ & 0.75 \\
\hline Latency to stand ( $\min )$ & $136.2 \pm 58.2$ & $150.2 \pm 66.2$ & - & $157.2 \pm 69.0$ & $189.2 \pm 84.8$ & 0.52 \\
\hline
\end{tabular}

${ }^{1}$ Descriptive statistics are based on the output for the general linear mixed models (GLMM).

${ }^{2}$ Cohen's $d$ was calculated to estimate the effect size of vitality at $95 \%$ CI for all behavioral parameters. 
effect on standing ability in calves with low vitality, but not in newborns with normal vitality (Table 2 ). In a recent study, Gladden et al. (2019) found no differences between control and ketoprofen-treated calves in the proportions of active behaviors (i.e., standing, walking, playing) within the first $48 \mathrm{~h}$ following birth; however, the authors did not assess the vitality of the newborn calves; only obstetrical assistance was considered.

Previous studies indicated that administering an NSAID at birth to calves may improve calf welfare. Pearson et al. (2019b) found no significant effect on physiological indicators of pain and inflammation in meloxicam-treated calves in comparison with placebotreated calves. In contrast, economically relevant factors such as increased growth or feed intake have been demonstrated in NSAID-treated neonatal calves (Todd et al., 2010; Murray et al., 2016a; Pearson et al., 2019a). Murray et al. (2016a) found significantly greater improvement in vigor from the first to the second vigor score assessment in calves that received meloxicam following birth than in calves that received the placebo solution. The authors also observed significantly greater milk intake in meloxicam-treated calves. These findings may support our results as both increased vigor and milk intake might correlate with greater standing ability reported here. Meloxicam treatment was associated with increased lying times in dairy cows either with cesarean section (Barrier et al., 2014) or dystocia (Swartz et al., 2018), which was considered as a sign of improved cow comfort by both researcher teams.

Although the ease of calving had small or moderate effects on long-term measures [the time spent standing (Cohen's $d=0.25,95 \% \mathrm{CI}$ ), the longest standing bout (Cohen's $d=0.52,95 \% \mathrm{CI}$ ), and the average duration of standing bouts (Cohen's $d=0.32,95 \% \mathrm{CI}$ )], the latency to stand and the first attempt to stand were both affected by calving ease (Cohen's $d=0.78$, and Cohen's $d=0.86$, respectively; $95 \%$ CI) with lower values of EUT calves $(114.2 \pm 59.6 \mathrm{~min}$ and $35.8 \pm$ $27.6 \mathrm{~min})$ compared with DYS calves $(208.2 \pm 82.1$ and $52.5 \pm 34.7 \mathrm{~min})$. In line with our findings, the ability of a calf to stand was decreased by dystocia (Barrier et al., 2013) and assisted calves tended to make standing attempts later (Campler et al., 2015) and took significantly longer to stand (Diesch et al., 2004) than calves born unassisted. No calving ease $\times$ treatment interaction was found and NSAID treatment itself did not affect short-term parameters of lying behavior (latency to stand: Cohen's $d=0.38$; the first attempt to stand: Cohen's $d=0.32$ ).

Recently we found that the duration of licking the calf is a prominent factor in the thermal and metabolic adaptation of newborn calves to extrauterine life (Kovács et al., 2017), whereas others stressed the onset and quality of maternal grooming as being main motivators of expressing neonatal behaviors including standing (Lidfors, 1996; Keyserlingk and Weary, 2007), which is fundamental in the expression of feeding behavior (Ventorp and Michanek, 1991). A previous study observed calves' first standing attempt at $21 \mathrm{~min}$ and successful standing around 51 min after delivery (Jensen, 2012). However, the average time it took for calves to stand in the present study was greater (around 143 min) and more in line with other findings that reported calves successfully standing within 88 to 152 min (Houwing et al., 1990; Campler et al., 2015). The latency for calves to stand is thought to be linked to the licking behavior of the dam shortly after birth (Lidfors, 1996); however, the time spent licking the calf had no meaningful effect on standing ability within the first $48 \mathrm{~h}$ of life in this study (Cohen's $d=0.20,95 \% \mathrm{CI}$ ), which can be explained with the early removal of the calves as the cow's ability to express grooming behavior was limited to $2 \mathrm{~h}$ after giving birth. A limitation of our study is that the time spent licking the calf could only be examined for the first $2 \mathrm{~h}$ after delivery; however, all procedures except for NSAID treatment had to be adapted to the daily routine of the farm. Although eutocic dams are more motivated to express maternal behaviors compared to dystocic dams (Jensen, 2012; Rørvang et al., 2018), no interaction between calving ease and time spent licking the calf was detected here. Barrier et al. (2012) also found that maternal behavior was unaffected by a difficult delivery.

\section{CONCLUSIONS}

To the best of our knowledge, this is the first report to use the analysis of complex lying behavior as a noninvasive approach to assess standing ability during the early postnatal life in dairy calves. Our results suggest sensory measurement of lying and standing behavior is a promising approach to evaluate the efficiency of NSAID protocols and meloxicam therapy shows considerable promise for improving short-term challenges with the adaptation of low-vitality calves, as shown by long-term measures of lying behavior. This might have longer-term effects on the health and survival of the calves, which should be further investigated.

\section{ACKNOWLEDGMENTS}

The authors thank Ferenc Bodó (farm owner), Ágoston Bodó (farm manager), and farm staff (Prograg Agrárcentrum Ltd., Ráckeresztúr, Lászlópuszta, Hungary), for supporting the study and taking care of the animals during the experiment. Levente Kovács was supported by the Országos Tudományos Kutatási Alap- 
programok (OTKA) Research Scholarship of the National Research, Development and Innovation Office, Budapest, Hungary (grant number: K-134204) and by the NTP-NFTÖ-20 project by the Human Capacities Grant Management Office and the Hungarian Ministry of Human Capacities, Budapest, Hungary (grant number: NTP-NFTÖ-20-B-0030). All study protocols are described in the manuscripts. Digital data that support the findings of the study are available in an online repository (https://doi.org/10.7910/DVN/IT1XJZ) without restriction. The authors have not stated any conflicts of interest.

\section{REFERENCES}

Anderson, D. E., and W. W. Muir. 2005. Pain management in cattle. Vet. Clin. North Am. Food Anim. Pract. 21:623-635. https://doi .org/10.1016/j.cvfa.2005.07.002.

Barrier, A. C., T. M. Coombs, C. M. Dwyer, M. J. Haskell, and L. Goby. 2014. Administration of a NSAID (meloxicam) affects lying behaviour after caesarean section in beef cows. Appl. Anim. Behav. Sci. 155:28-33. https://doi.org/10.1016/j.applanim.2014.02.015.

Barrier, A. C., M. J. Haskell, S. Birch, A. Bagnall, D. J. Bell, J. Dickinson, A. I. Macrae, and C. M. Dwyer. 2013. The impact of dystocia on dairy calf health, welfare, performance and survival. Vet. J. 195:86-90. https://doi.org/10.1016/j.tvjl.2012.07.031.

Barrier, A. C., E. Ruelle, M. J. Haskell, and C. M. Dwyer. 2012. Effect of a difficult calving on the vigour of the calf, the onset of maternal behaviour, and some behavioural indicators of pain in the dam. Prev. Vet. Med. 103:248-256. https://doi.org/10.1016/j .prevetmed.2011.09.001.

Beretta, C., G. Garavaglia, and M. Cavalli. 2005. COX-1 and COX-2 inhibition in horse blood by phenylbutazone, flunixin, carprofen and meloxicam: An in vitro analysis. Pharmacol. Res. 52:302-306. https://doi.org/10.1016/j.phrs.2005.04.004.

Besser, T. E., O. Szenci, and C. C. Gay. 1990. Decreased colostral immunoglobulin absorption in calves with postnatal respiratory acidosis. J. Am. Vet. Med. Assoc. 196:1239-1243.

Bonk, S., O. Burfeind, V. S. Suthar, and W. Heuwieser. 2013. Technical note: Evaluation of data loggers for measuring lying behavior in dairy calves. J. Dairy Sci. 96:3265-3271. https://doi.org/10 $.3168 / \mathrm{jds} .2012-6003$.

Breazile, J. E., L. A. Vollmer, and L. E. Rice. 1988. Neonatal adaptation to stress of parturition and dystocia. Vet. Clin. North Am. Food Anim. Pract. 4:481-499. https://doi.org/10.1016/S0749 $-0720(15) 31026-4$.

Brideau, C., C. Van Staden, and C. C. Chan. 2001. In vitro effects of cyclooxygenase inhibitors in whole blood of horses, dogs, and cats. Am. J. Vet. Res. 62:1755-1760. https://doi.org/10.2460/ajvr.2001 .62.1755.

Campler, M., L. Munksgaard, and M. B. Jensen. 2015. The effect of housing on calving behavior and calf vitality in Holstein and Jersey dairy cows. J. Dairy Sci. 98:1797-1804. https://doi.org/10 $.3168 /$ jds.2014-8726.

Clark, M. O. C., T. C. Stahl, and P. S. Erickson. 2020. The effect of meloxicam on neonatal dairy calves: Immunoglobulin G uptake and preweaning performance. J. Dairy Sci. 103:11363-11374. https://doi.org/10.3168/jds.2020-18501.

Coetzee, J. F., B. KuKanich, R. Mosher, and P. S. Allen. 2009. Pharmacokinetics of intravenous and oral meloxicam in ruminant calves. Vet. Ther. 10:E1-E8.

Coetzee, J. F. 2013. Assessment and management of pain associated with castration in cattle. Vet. Clin. North Am. Food Anim. Pract. 29:75-101. https://doi.org/10.1016/j.cvfa.2012.11.002.

Diesch, T. J., D. J. Mellor, K. J. Stafford, and R. N. Ward. 2004. The physiological and physical status of single calves at birth in a dairy herd in New Zealand. N. Z. Vet. J. 52:250-255. https://doi.org/10 $.1080 / 00480169.2004 .36436$.

European Agency for the Evaluation of Medicinal Products. 2007. Scientific Discussion, Metacam. CVMP/323/97: London, UK. Accessed October 29, 2021. https://www.ema.europa.eu/en/documents/ scientific-discussion/metacam-epar-scientific-discussion_en.pdf.

Gladden, N., K. Ellis, J. Martin, L. Viora, and D. McKeegan. 2019. A single dose of ketoprofen in the immediate postpartum period has the potential to improve dairy calf welfare in the first $48 \mathrm{~h}$ of life. Appl. Anim. Behav. Sci. 212:19-29. https://doi.org/10.1016/j applanim.2019.01.007.

Heinrich, A., T. F. Duffield, K. D. Lissemore, and S. T. Millman. 2010. The effect of meloxicam on behavior and pain sensitivity of dairy calves following cautery dehorning with a local anesthetic. J. Dairy Sci. 93:2450-2457. https://doi.org/10.3168/jds.2009-2813.

Heinrich, A., T. F. Duffield, K. D. Lissemore, E. J. Squires, and S. T. Millman. 2009. The impact of meloxicam on postsurgical stress associated with cautery dehorning. J. Dairy Sci. 92:540-547. https:/ /doi.org/10.3168/jds.2008-1424.

Houwing, H., J. F. Hurnik, and N. J. Lewis. 1990. Behavior of periparturient dairy cows and their calves. Can. J. Anim. Sci. 70:355-362. https://doi.org/10.4141/cjas90-047.

Huxley, J. N., and H. R. Whay. 2006. Current attitudes of cattle practitioners to pain and the use of analgesics in cattle. Vet. Rec. 159:662-668. https://doi.org/10.1136/vr.159.20.662.

Jensen, M. B. 2012. Behaviour around the time of calving in dairy cows. Appl. Anim. Behav. Sci. 139:195-202. https://doi.org/10 .1016/j.applanim.2012.04.002.

Kovács, L., F. L. Kézér, E. Albert, F. Ruff, and O. Szenci. 2017. Seasonal and maternal effects on acid-base, lactate, electrolyte and hematological status of 205 dairy calves born to eutocic dams. J. Dairy Sci. 100:7534-7543. https://doi.org/10.3168/jds.2017-12543.

Kovács, L., F. L. Kézér, M. Bakony, V. Jurkovich, and O. Szenci 2018. Lying down frequency as a discomfort index in heat stressed Holstein bull calves. Sci. Rep. 8:15065. https://doi.org/10.1038/ s41598-018-33451-6.

Kovács, L., F. L. Kézér, and O. Szenci. 2016. Effect of calving process on the outcomes of delivery and postpartum health of dairy cows with unassisted and assisted calvings. J. Dairy Sci. 99:7568-7573. https://doi.org/10.3168/jds.2016-11325.

Ledgerwood, D. N., C. Winckler, and C. B. Tucker. 2010. Evaluation of data loggers, sampling intervals, and editing techniques for measuring the lying behavior of dairy cattle. J. Dairy Sci. 93:51295139. https://doi.org/10.3168/jds.2009-2945.

Lidfors, L. M. 1996. Behavioural effects of separating the dairy calf immediately or 4 days post-partum. Appl. Anim. Behav. Sci. 49:269 283. https://doi.org/10.1016/0168-1591(96)01053-2.

Lombard, J. E., F. B. Garry, S. M. Tomlinson, and L. P. Garber. 2007. Impacts of dystocia on health and survival of dairy calves. J. Dairy Sci. 90:1751-1760. https://doi.org/10.3168/jds.2006-295.

Mee, J. F. 2004. Managing the dairy cow at calving time. Vet. Clin. North Am. Food Anim. Pract. 20:521-546. https://doi.org/10 .1016/j.cvfa.2004.06.001.

Mee, J. F. 2008. Newborn dairy calf management. Vet. Clin. North Am. Food Anim. Pract. 24:1-17. https://doi.org/10.1016/j.cvfa 2007.10.002.

Mee, J. F. 2013. Why do so many calves die on modern dairy farms and what can we do about calf welfare in the future? Animals (Basel) 3:1036-1057. https://doi.org/10.3390/ani3041036.

Mellor, D. J., and K. J. Stafford. 2004. Animal welfare implications of neonatal mortality and morbidity in farm animals. Vet. J. $168: 118-133$.

Moggy, M. A., E. A. Pajor, W. E. Thurston, S. Parker, A. M. Greter, K. S. Schwartzkopf-Genswein, J. R. Campbell, and M. C. Windeyer. 2017. Management practices associated with pain in cattle on Western Canadian cow-calf operations: A mixed methods study. J. Anim. Sci. 95:958-969. https://doi.org/10.2527/jas2016.0949.

Murray, C. F., T. F. Duffield, D. B. Haley, D. L. Pearl, D. M. Veira, S. M. Deelen, and K. E. Leslie. 2016a. The effect of meloxicam NSAID therapy on the change in vigor, suckling reflex, blood gas 
measures, milk intake and other variables in newborn dairy calves. J. Vet. Sci. Anim. Husb. 4:1-14.

Murray, C. F., L. J. Fick, E. A. Pajor, H. W. Barkema, M. D. Jelinski, and M. C. Windeyer. 2016b. Calf management practices and associations with herd-level morbidity and mortality on beef cowcalf operations. Animal 10:468-477. https://doi.org/10.1017/ S1751731115002062.

Murray, C. F., and K. E. Leslie. 2013. Newborn calf vitality: Risk factors, characteristics, assessment, resulting outcomes and strategies for improvement. Vet. J. 198:322-328. https://doi.org/10.1016/j .tvjl.2013.06.007.

Pearson, J. M., E. A. Pajor, J. R. Campbell, N. A. Caulkett, M. Levy, C. Dorin, and M. C. Windeyer. 2019a. Clinical impacts of administering a nonsteroidal anti-inflammatory drug to beef calves after assisted calving on pain and inflammation, passive immunity, health, and growth. J. Anim. Sci. 97:1996-2008. https://doi.org/ $10.1093 / j a s /$ skz094.

Pearson, J. M., E. A. Pajor, J. R. Campbell, M. Levy, N. A. Caulkett, and M. C. Windeyer. 2019b. A randomised controlled trial investigating the effects of administering a non-steroidal antiinflammatory drug to beef calves assisted at birth and risk factors associated with passive immunity, health, and growth. Vet. Rec. Open 6:e000364. https://doi.org/10.1136/vetreco-2019-000364.

Pinheiro, J. C., and D. M. Bates. 2000. Mixed-Effects Models in S and S-PLUS. 1st ed. Springer.

Rørvang, M. V., B. L. Nielsen, M. S. Herskin, and M. B. Jensen. 2018. Prepartum maternal behavior of domesticated cattle: A comparison with managed, feral, and wild ungulates. Front. Vet. Sci. 5:45. https://doi.org/10.3389/fvets.2018.00045.

Schuijt, G. 1990. Iatrogenic fractures of ribs and vertebrae during delivery in perinatally dying calves: 235 cases (1978-1988). J. Am. Vet. Med. Assoc. 197:1196-1202.

Swartz, T. H., M. L. McGilliard, and C. S. Petersson-Wolfe. 2016. Technical note: The use of an accelerometer for measuring step activity and lying behaviors in dairy calves. J. Dairy Sci. 99:91099113. https://doi.org/10.3168/jds.2016-11297.
Swartz, T. H., H. H. Schramm, J. M. Bewley, C. M. Wood, K. E. Leslie, and C. S. Petersson-Wolfe. 2018. Meloxicam administration either prior to or after parturition: Effects on behavior, health, and production in dairy cows. J. Dairy Sci. 101:10151-10167. https:// doi.org/10.3168/jds.2018-14657.

Szenci, O. 1982. Correlations between muscle tone and acid-base balance in newborn calves: experimental substantiation of a simple new score system proposed for neonatal status diagnosis. Acta Vet Acad Sci Hung. 30:79-84.

Szenci, O. 2003. Role of acid-base disturbances in perinatal mortality of calves. Vet. Bull. 73:7R-14R. (review).

Todd, C. G., S. T. Millman, D. R. McKnight, T. F. Duffield, and K. E. Leslie. 2010. Nonsteroidal antiinflammatory drug therapy for neonatal calf diarrhea complex: Effects on calf performance. J. Anim. Sci. 88:2019-2028. https://doi.org/10.2527/jas.2009-2340.

Ventorp, M., and P. Michanek. 1991. Cow-calf behaviour in relation to first suckling. Res. Vet. Sci. 51:6-10. https://doi.org/10.1016/ 0034-5288(91)90022-G.

Vermorel, M., C. Dardillat, J. Vernet, and C. Demigne. 1983. Energy metabolism and thermoregulation in the newborn calf. Ann. Rech. Vet. 14:382-389.

von Keyserlingk, M. A. G., and D. M. Weary. 2007. Maternal behavior in cattle. Horm. Behav. 52:106-113.

Ward, J. 1973. Week calf syndrome. Pages 97-103 in Proceedings of the 6th Annual Convention of American Association of Bovine Practitioners. Texas Digital Library.

\section{ORCIDS}

L. Kovács @ https://orcid.org/0000-0001-9149-404X

M. Samardzija ๑ https://orcid.org/0000-0003-0402-3173

O. Szenci 『 https://orcid.org/0000-0002-3248-173X 